\title{
Highly Elevated Levels and Particle-Size Distributions of Environmentally Persistent Free Radicals in Haze-Associated Atmosphere
}

\author{
Lili Yang, ${ }^{\dagger \dagger}$ Guorui Liu, ${ }^{*},+\ddagger$ Minghui Zheng, ${ }^{*}, \dagger$ Rong Jin, ${ }^{\dagger, \ddagger}$ Qingqing Zhu, ${ }^{\dagger, \ddagger}$ Yuyang Zhao, ${ }^{\dagger, \ddagger}$ \\ Xiaolin $\mathrm{Wu}^{\dagger, \dagger}$ and Yang $\mathrm{Xu}^{\dagger, \ddagger}$
}

${ }^{\dagger}$ State Key Laboratory of Environmental Chemistry and Ecotoxicology, Research Center for Eco-Environmental Sciences, Chinese Academy of Sciences, P.O. Box 2871, Beijing 100085, China

${ }^{\ddagger}$ University of Chinese Academy of Sciences, Beijing 100049, China

Supporting Information

ABSTRACT: Levels and particle-size distributions of environmentally persistent free radicals (EPFRs) in haze-associated atmospheric particulate matter (PM) have not been highlighted, even though they may enter the human body along with PM and adversely affect human health. This study quantified the levels of EPFRs in airborne PM with different aerodynamic diameters $\left(d_{\mathrm{ae}}\right)$ using electron paramagnetic resonance (EPR) spectroscopy. EPR spectra showed a single, unstructured signal from persistent semiquinone radicals. The average concentration of EPFRs in the airborne PM during haze events was $2.18 \times$ $12^{20}$ spins/g (range: $3.06 \times 10^{19}-6.23 \times 10^{20}$ spins $/ g$ ), approximately 2 orders of magnitude higher than that reported previously in the US atmosphere. Particle-size distributions of EPFRs in four different PM fractions $\left(d_{\mathrm{ae}}>10 \mu \mathrm{m}, 10 \mu \mathrm{m}<d_{\mathrm{ae}}<2.5 \mu \mathrm{m}, 2.5 \mu \mathrm{m}<d_{\mathrm{ae}}<1 \mu \mathrm{m}, d_{\mathrm{ae}}<1 \mu \mathrm{m}\right)$ indicated the highest levels of EPFRs in the PM fraction with $d_{\mathrm{ae}}<1 \mu \mathrm{m}$, with average 1/e lifetime of 59.2 days. A significant occurrence of EPFRs in PM samples collected from coal-burning activities $\left(1.52 \times 10^{22} \mathrm{spins} / \mathrm{g}\right)$, automobile exhaust $\left(3.0 \times 10^{22} \mathrm{spins} / \mathrm{g}\right)$, and biomass burning activities $\left(1.14 \times 10^{22}\right.$ spins/g) was detected, which may be potential primary sources of EPFRs in airborne PM. The results in this study may help to understand the sources and potential risks of EPFRs in airborne fine particles.

\section{INTRODUCTION}

Environmentally persistent free radicals (EPFRs) are a category of emerging surface-stabilized pollutants. ${ }^{1,2}$ Unlike short-lived free radicals of traditional concern, EPFRs are not highly reactive with molecular species and can be stable in the environment. ${ }^{3}$ Furthermore, EPFRs may induce a generation of harmful reactive oxygen species that cause DNA damage. ${ }^{4}$ It has been proposed that the half-life of EPFRs (1/e lifetime) in environmental matrices can be several days or several months and even indefinitely on the internal surface of fine particles. ${ }^{5,6}$ Therefore, the detrimental effect of EPFRs on human health may be much more persistent considering their far longer lifetime. Consequently, the effect of EPFRs on human health has recently attracted increasing attention, as EPFRs may be one of the main components governing the behavior and activity of particulate matter (PM). ${ }^{4,7}$ In spite of the direct health effects, EPFRs have also been identified to be important intermediates for organic pollutant formation such as halogenated dioxin produced during heterogeneous catalysis. $^{8-11}$ Therefore, further studies associated with the occurrence and distribution of EPFRs in various environmental

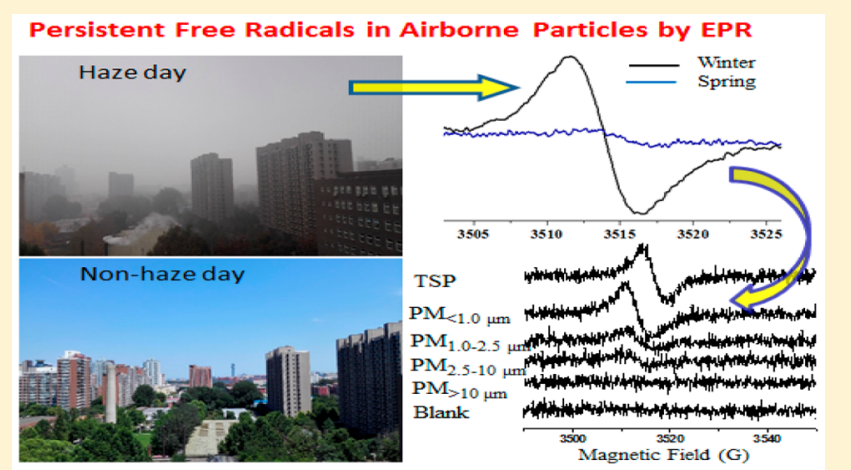

matrices are essential for better understanding the environmental effect and potential human risk exposures to EPFRs.

Several studies have reported the occurrence of EPFRs in diesel exhaust, total suspended particulates in air, and soil and sediment contaminated by EPFR precursors such as chlorophenol, chlorobenzene, and polycyclic aromatic hydrocarbon. ${ }^{5,12-16}$ Airborne fine particles may be one of the important carriers of EPFRs. ${ }^{5}$ Thus, the occurrence of EPFRs in airborne fine particles might pose potential adverse effects on human health by air inhalation of airborne PM, especially for the respiratory system. The concentrations of PM with aerodynamic diameters $\left(d_{\mathrm{ae}}\right)$ lower than $2.5 \mu \mathrm{m}\left(\mathrm{PM}_{2.5}\right)$ can be several hundred micrograms per cubic meter $\left(\mu \mathrm{g} / \mathrm{m}^{3}\right)$ in haze events in some Chinese cities. The health impacts of $\mathrm{PM}_{2.5}$ are of increasing concern because of its harmful effect on human health such as pulmonary, immune, and cardiovascular disorders. ${ }^{17-19}$ Understanding the composition of ambient

Received: April 13, 2017

Revised: June 12, 2017

Accepted: June 14, 2017

Published: June 14, 2017 

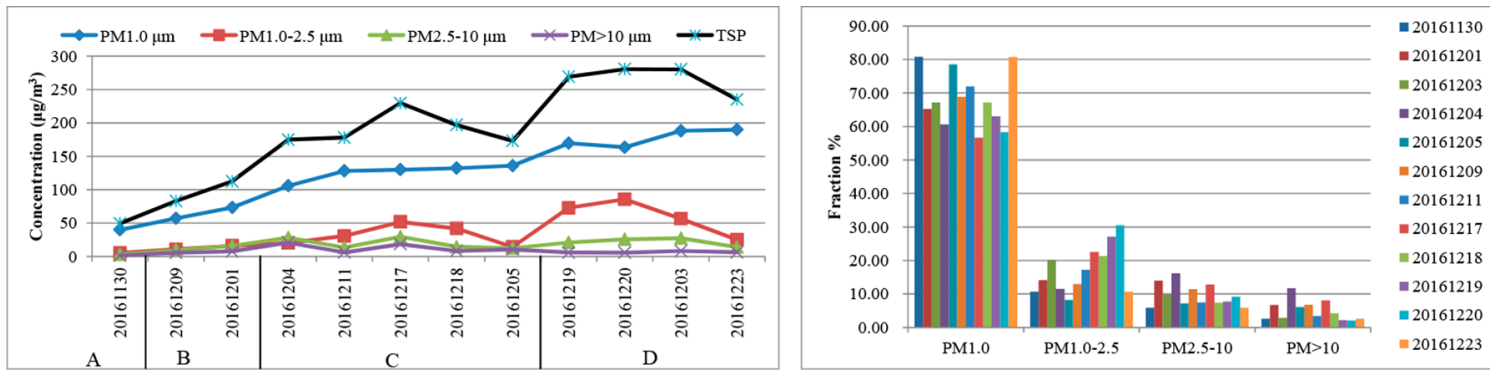

Figure 1. Size distribution of particulate matter collected during one month of the heating period in Beijing.

particles that determine their behavior and toxicity is a principal step for controlling their health effects. The occurrence of EPFRs on fine particles has been identified and is persistent in part because of chemisorption to the metal oxide and surface stabilization on fine particles. ${ }^{1,3,20,21}$ EPFRs on PM are redox active and more cytotoxic than well-known individual organic pollutants in biological systems. ${ }^{2,3,19,20}$ However, the consequences of human population exposure to EPFRs in airborne $\mathrm{PM}$, especially in haze events, remain unclear, owing to the lack of knowledge regarding the levels and particle-size distributions of EPFRs in airborne PM.

Haze events in Beijing have attracted increasing public concern in recent years. ${ }^{2,23}$ The hourly maximum $\mathrm{PM}_{2.5}$ concentration was $626 \mu \mathrm{g} \mathrm{m}^{-3}$ in the haze episode that occurred between November 26 and December 1, 2015, which was 8 times that of the Chinese National Ambient Air Quality Standard $\left(24 \mathrm{~h}\right.$ means of $\left.75 \mu \mathrm{g} \mathrm{m}^{-3}\right){ }^{24}$ However, no study has quantified the levels of EPFRs in airborne PM during haze events, so whether the haze events noticeably increase the EPFR levels in airborne PM has remained unclear. Differentsized PM may reach dissimilar depths of the respiratory system and lead to differential health effects. ${ }^{25-27}$ It has also been demonstrated that the toxicity of PM with varying sizes and compositions is different. ${ }^{28,29}$ Previous studies have also confirmed different loads of notorious toxic persistent organic pollutants (POPs) in airborne fine particles of various sizes. ${ }^{30,31}$ Therefore, it is vital to clarify the levels and particle-size distributions of EPFRs in airborne PM with the aim of better understanding the potential health risks owing to air inhalation of EPFRs in airborne fine particles, especially during haze events.

In this study, $\mathrm{PM}$ with different aerodynamic diameters $\left(\mathrm{PM}_{>10 \mu \mathrm{m}}: d_{\mathrm{ae}}>10 \mu \mathrm{m} ; \mathrm{PM}_{2.5-10 \mu \mathrm{m}}: 10 \mu \mathrm{m}<d_{\mathrm{ae}}<2.5 \mu \mathrm{m}\right.$; $\left.\mathrm{PM}_{1-2.5 \mu \mathrm{m}}: 2.5 \mu \mathrm{m}<d_{\mathrm{ae}}<1 \mu \mathrm{m} ; \mathrm{PM}_{<1 \mu \mathrm{m}}: d_{\mathrm{ae}}<1 \mu \mathrm{m}\right)$ were collected during haze days and also nonhaze days as a control. The levels of EPFRs in airborne PM with different air concentrations were quantified, and their particle-size distributions were determined, which may provide important data for better evaluation of the potential health risks caused by exposure to EPFRs on fine particles. Moreover, clarification of EPFR particle-size distribution in PM may provide helpful information for better study of their transport and fate in the atmosphere, as the missing sink for radicals proposition, a phenomenon regarding the unknown whereabouts of radicals during the biogeochemical cycle, may be attributed to multiphase reactions on aerosol particles. ${ }^{32}$ Currently, little available knowledge regarding the primary sources of EPFRs in PM during haze events exist. Therefore, PM samples collected from coal burning-associated activities, biomass burningassociated activities, automobile exhaust, a waste incineration process, and metallurgical plants, which are widely recognized as potential primary sources of airborne fine particles were also evaluated for EPFR occurrence by electron paramagnetic resonance (EPR) spectroscopy with the aim of confirming whether these human activities are also potential sources of EPFRs in airborne fine particles.

\section{MATERIALS AND METHODS}

Sampling of Airborne Fine Particles. Different size airborne PM samples were collected by a high-volume aerosol sampler (KS-303, Kálmán, Budapest, Hungary), with a sampling flow rate of $400 \mathrm{~L} \mathrm{~min}^{-1}$, capable of dividing the total suspension particles (TSP) into four PM fractions $\left(d_{\mathrm{ae}}>\right.$ $\left.10 \mu \mathrm{m}, 10 \mu \mathrm{m}<d_{\mathrm{ae}}<2.5 \mu \mathrm{m}, 2.5 \mu \mathrm{m}<d_{\mathrm{ae}}<1 \mu \mathrm{m}, d_{\mathrm{ae}}<1 \mu \mathrm{m}\right)$ through the cascade impactor. Another high-volume sampler (Echo Hi-Vol, Tecora, Milan, Italy) was used for separately collecting TSP samples, with a sampling flow rate of $280 \mathrm{~L}$ $\mathrm{min}^{-1}$. The duration time for all PM sample collections was approximately $24 \mathrm{~h}$. Quartz fiber filters (Ahlstrom Munktell, Sweden), which were baked at $450{ }^{\circ} \mathrm{C}$ to remove potential organic contaminants, were used for the collection of particulate samples. Detailed information on the fiber filters are given in our previous study. ${ }^{30}$ The filters were weighed accurately after drying under controlled temperature $(20 \pm 5$ $\left.{ }^{\circ} \mathrm{C}\right)$ and humidity $(30 \pm 2 \%)$, both before and after sample collection for the calculation of particle mass concentration. Polyurethane foam (PUF, $63 \mathrm{~mm}$ diameter and $76 \mathrm{~mm}$ length, Tisch Environmental, USA), prepurified by accelerated solvent extraction (Thermo Fisher Scientific, USA) with acetone before use, was used for the synchronous collection of the gas phase along with the PM. After collection, samples were wrapped tightly in aluminum foil and kept at $18{ }^{\circ} \mathrm{C}$ for $24 \mathrm{~h}$. The sampling site was located at the urban ecosystem research station $\left(116.34^{\circ} \mathrm{E}, 40.01^{\circ} \mathrm{N}\right)$ in Beijing, China, with universities and residential areas nearby.

In this study, air conditions were subdivided into four different levels according to mass concentrations of $\mathrm{PM}_{<1 \mu \mathrm{m}}$. Samples of mass concentrations of $\mathrm{PM}_{<1 \mu \mathrm{m}}$ below $50 \mu \mathrm{g} / \mathrm{m}^{3}$, $50-100 \mu \mathrm{g} / \mathrm{m}^{3}, 100-150 \mu \mathrm{g} / \mathrm{m}^{3}$, and $150-200 \mu \mathrm{g} / \mathrm{m}^{3}$ were labeled as sample series A, B, C, and D, respectively, which indicated days of free, mild, moderate, and heavy air pollution. ${ }^{31}$ As shown in Figure 1, the continuous sampling was conducted from November 30 to December 23, 2016 in the winter when haze events occurred frequently. During the winter, a large amount of coal is combusted to provide warmth in north China including Beijing, and this season is known as the heating period. In total, 12 samples, including one sample from a pollution-free day, two samples from mild pollution days, five samples from moderate pollution days, and four samples from heavy pollution days, were collected during the 
heating period. To evaluate the potential contributions of coal burning to the occurrence of EPFRs in airborne PM, TSP samples collected on haze days with a $\mathrm{PM}_{<1.0 \mu \mathrm{m}}$ concentration of approximately $120 \mu \mathrm{g} / \mathrm{m}^{3}$ on March 3, 2016 during the spring (nonheating period) was also collected and analyzed to compare with samples having a similar $\mathrm{PM}_{<1.0 \mu \mathrm{m}}$ concentration in the winter. In addition, automobile exhaust, biomass burning ash, and fly ashes of different industrial plants were also collected to explore the possible primary sources of EPFRs in atmospheric PM. Fly ash samples produced during waste incineration, coking, and secondary metal smelting stages, which may easily diffuse into the atmosphere, were collected from the air pollution control device. Coke was produced by carbonization of coal in the absence of air at approximately $1000{ }^{\circ} \mathrm{C}$ in coke ovens. Coking ash was the fly ash produced from coke production. Biomass burning ash was the solid residue after combustion of the biomass mixture including bulrush, branch, and straw. The gasoline exhaust particles deposited in the exhaust pipes were also collected by glass microfiber filters.

Sample Pretreatment, EPFR Detection by EPR, and PM Characterization by SEM-EDX Spectroscopy. It has been reported that organic free radicals and contaminants can be extracted by organic solvents. ${ }^{33}$ In this study, sample pretreatment was conducted according to a method modified from previous studies. ${ }^{33}$ The quartz filters with the collected fine particles were cut into pieces and added to a centrifugal glass tube with $20 \mathrm{~mL}$ of dichloromethane. The tube was slightly shaken for $3 \mathrm{~min}$, and then the filter pieces were steeped in the solvent for $6 \mathrm{~h}$ in a dark environment. After transferring the supernatant to another tube, the filter membranes were rinsed repeatedly in triplicate. To evaluate the extraction efficiency, the PM samples were extracted again using the same procedure, and EPFRs were detected by EPR. The EPR signal in the extraction solution from the second round of treatment was approximately $2.5 \%$ of that in the first extraction solutions, indicating that the extraction efficiency was acceptable when using the established extraction procedure. The supernatant and rinse solutions were combined and evaporated to approximately $100 \mu \mathrm{L}$ by a gentle stream of nitrogen. A blank quartz filter used as the blank sample was treated in the same manner as each batch of samples to confirm that there was no obvious EPFR contamination from the quartz fiber filters and the pretreatment process.

Scanning electron microscopy with energy dispersive X-ray spectroscopy (SEM-EDX) is a powerful tool for characterization of surface morphology and chemical compositions of solid materials. In the present study, SEM-EDX was used to characterize the morphology and constitution of airborne fine particle samples and PM collected from coal-burning-associated activities, automobile exhaust, and metallurgical plants. SEMEDX was able to visualize the differences between PM from different sources. SEM-EDX was carried out on a Hitachi SU8020 SEM (Hitachi, Ltd., Tokyo, Japan) operating at $15 \mathrm{kV}$ with a probe current of $0.6 \mathrm{nA}$ and interfaced with a Bruker silicon drift detector EDS system (Bruker Instruments, Billerica, MA).

EPR spectra of PM filters for EPFR analysis were measured using a Bruker EMX-plus X-band EPR spectrometer. The instrument and operating parameters were as follows: center field, $3520 \mathrm{G}$; microwave frequency, $9.36 \mathrm{GHz}$; microwave power, $0.63 \mathrm{~mW}$; modulation frequency, $100 \mathrm{kHz}$; modulation amplitude, $1.0 \mathrm{G}$; sweep width, $200 \mathrm{G}$; receiver gain, $30 \mathrm{~dB}$; and time constant, $0.01 \mathrm{~ms}$. Radical quantification was conducted using Bruker's Xenon program, resulting in radical number of spins for the PM samples (spins $/ \mathrm{m}^{3}$ ). The area under the EPR single broad peak represented a quantitative measure of radical spins in the sample. The g-factors were determined by Bruker's WinEPR program. All measurements were conducted at room temperature.

Method for Evaluating the Decay of EPFRs Extracted from Airborne PM. Organic radicals are typically reactive and short-lived; however, radicals bound to particles can be persistent in environmental matrices. ${ }^{1,3,13,16,20,21,34}$ Therefore, kinetic studies were conducted to determine the persistence of EPFRs extracted from the PM. Fibers were continuously exposed to ambient air and stored in a controlled temperature and humidity incubator. After pretreatment, solution extracts were periodically measured by EPR as a function of time. Extracts placed in quartz tubes were stored in $4{ }^{\circ} \mathrm{C}$ freezers between each measurement. Because of the major proportion of EPFRs in $\mathrm{PM}_{<1 \mu \mathrm{m}}$ determined in our study, the 1/e lifetime $\left(t_{1 / \mathrm{e}}\right)$ of EPFRs extracted from $\mathrm{PM}_{<1 \mu \mathrm{m}}$ were evaluated according to the pseudo-first-order integrated rate law expression as follows: ${ }^{16,35-37}$

$$
\begin{aligned}
& \ln \left(C / C_{0}\right)=-k t \\
& t_{1 / \mathrm{e}}=1 / k
\end{aligned}
$$

where $k$ is the rate constant, derived from the slope of the logarithm of the radical concentration ratio $\left(C / C_{0}\right)$ versus time, and $t_{1 / \mathrm{e}}$ was obtained thereby.

\section{RESULTS AND DISCUSSION}

Levels and Particle-Size Distribution of EPFRs in Airborne PM. Mass concentrations of TSP at the sampling site during the sampling periods (heating period in winter when haze events happened frequently) in Beijing ranged from 49 to $281 \mu \mathrm{g} / \mathrm{m}^{3}$. Corresponding mass concentrations of four PM fractions classified as $\mathrm{PM}_{<1 \mu \mathrm{m}}, \mathrm{PM}_{1.0-2.5 \mu \mathrm{m}}, \mathrm{PM}_{2.5-10 \mu \mathrm{m}}$ and $\mathrm{PM}_{>10 \mu \mathrm{m}}$ were in the ranges of $40-190 \mu \mathrm{g} / \mathrm{m}^{3}, 5-86 \mu \mathrm{g} / \mathrm{m}^{3}$, $3-30 \mu \mathrm{g} / \mathrm{m}^{3}$, and $1-21 \mu \mathrm{g} / \mathrm{m}^{3}$, respectively (shown in Table $\mathrm{S} 1)$. As shown in Figure 1 , the $\mathrm{PM}_{<1 \mu \mathrm{m}}$ fraction contributed $58 \%-81 \%$ of the total PM mass, which indicated that much more $\mathrm{PM}$ in the atmosphere was present in smaller size fractions.

Radicals, when attached to surfaces, can be stabilized. ${ }^{2}$ Therefore, surface-mediated EPFRs can easily occur in atmospheric PM, though EPFRs may undergo scavenging processes via self-reactions in the gas phase. ${ }^{3}$ To confirm whether EPFRs can exist in the gas phase, potential organic chemicals or radicals in atmospheric gas were also trapped using PUF absorbent under the same collection conditions as the PM used in this study. As expected, EPFRs were not detected in the gas phase, even on the haze days with a high $\mathrm{PM}_{<1 \mu \mathrm{m}}$ concentration in the range of $150-200 \mu \mathrm{g} / \mathrm{m}^{3}$. Moreover, to avoid insufficient sample volume collection, one $2800-\mathrm{m}^{3}$ gas phase sample was collected continuously over 1 week, and the results further confirmed few EPFR occurrences in atmospheric gas, even on heavy haze days.

As for the PM, EPR signals from sample series A, whose mass concentration of $\mathrm{PM}_{<1 \mu \mathrm{m}}$ was below $50 \mu \mathrm{g} / \mathrm{m}^{3}$, were not detected in the TSP, $\mathrm{PM}_{<1 \mu \mathrm{m}}, \mathrm{PM}_{1.0-2.5 \mu \mathrm{m}}, \mathrm{PM}_{2.5-10 \mu \mathrm{m}}$ and $\mathrm{PM}_{>10 \mu \mathrm{m}}$. EPR signals from all investigated samples were not detected in $\mathrm{PM}_{>10 \mu \mathrm{m}}$. The mean concentrations of EPFRs in TSP, $\mathrm{PM}_{<1 \mu \mathrm{m}}, \mathrm{PM}_{1.0-2.5 \mu \mathrm{m}}$ and $\mathrm{PM}_{2.5-10 \mu \mathrm{m}}$ on mild pollution 

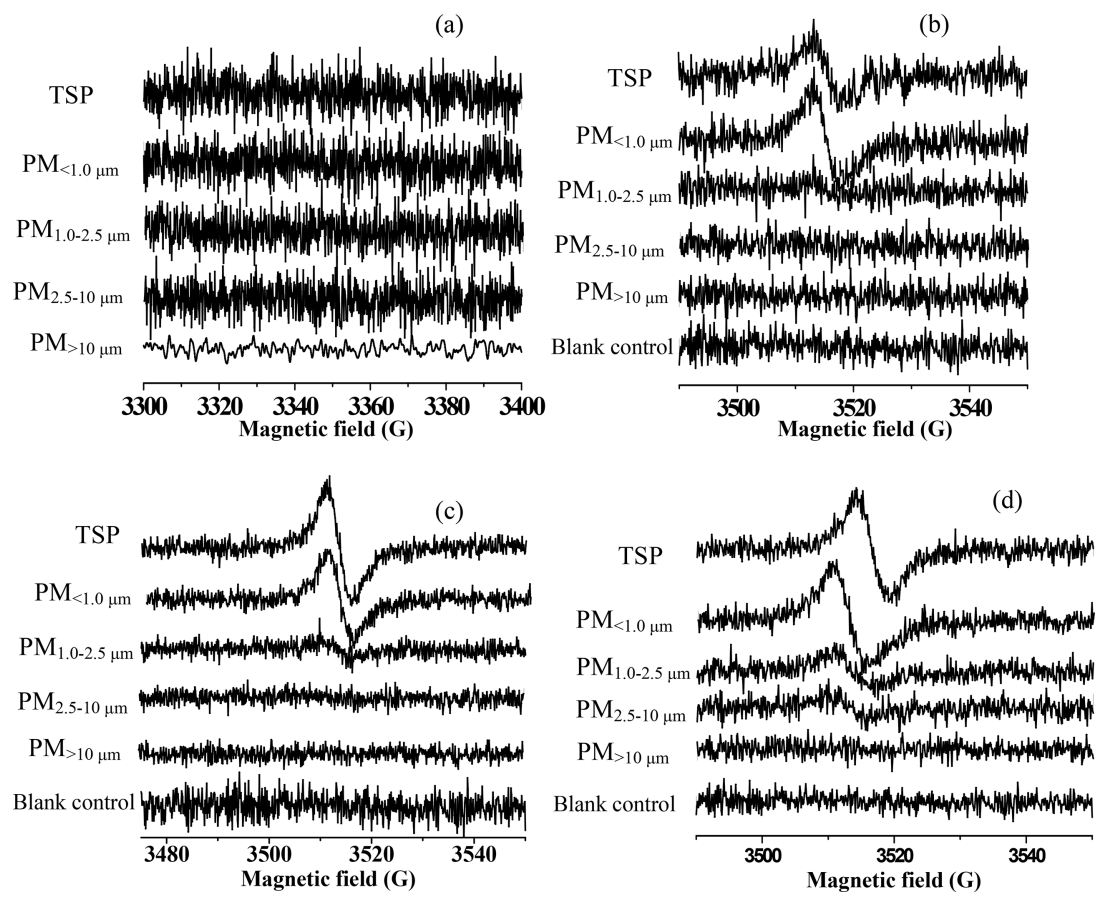

Figure 2. Electron paramagnetic resonance spectra for particulate matter of different diameters collected on days with different air conditions classified by mass concentrations of $\mathrm{PM}_{<1 \mu \mathrm{m}}$ (a) below $50 \mu \mathrm{g} / \mathrm{m}^{3}$, (b) $50-100 \mu \mathrm{g} / \mathrm{m}^{3}$, (c) $100-150 \mu \mathrm{g} / \mathrm{m}^{3}$, and (d) $150-200 \mu \mathrm{g} / \mathrm{m}^{3}$.

days (sample series B) were in the range of $8.9 \times 10^{15}$ to $3.9 \times$ $10^{16}$ spins $/ \mathrm{m}^{3}, 1.1 \times 10^{16}$ to $1.9 \times 10^{16}$ spins $/ \mathrm{m}^{3}, 1.0 \times 10^{15}$ to $1.7 \times 10^{15}$ spins $/ \mathrm{m}^{3}$, and $\mathrm{ND}$ to $9.8 \times 10^{13} \mathrm{spins} / \mathrm{m}^{3}$, respectively, while the mean concentrations on moderate pollution days (sample series $\mathrm{C}$ ) were in the range of $8.9 \times$ $10^{15}$ to $3.9 \times 10^{16} \mathrm{spins} / \mathrm{m}^{3}, 2.5 \times 10^{15}$ to $3.9 \times 10^{16} \mathrm{spins} / \mathrm{m}^{3}$, $1.8 \times 10^{15}$ - to $6.7 \times 10^{15}$ spins $/ \mathrm{m}^{3}$, and $\mathrm{ND}$ to $7.8 \times 10^{14}$ spins $/ \mathrm{m}^{3}$, respectively. For serious haze days (sample series D), the mean concentrations of EPFRs in TSP, $\mathrm{PM}_{<1 \mu \mathrm{m}}$, $\mathrm{PM}_{1.0-2.5 \mu \mathrm{m}}$ and $\mathrm{PM}_{2.5-10 \mu \mathrm{m}}$ were in the range of $1.6 \times 10^{16}$ to $4.5 \times 10^{16}$ spins $/ \mathrm{m}^{3}, 2.7 \times 10^{16}$ to $3.5 \times 10^{16}$ spins $/ \mathrm{m}^{3}, 2.9 \times$ $10^{15}$ to $1.4 \times 10^{16} \mathrm{spins} / \mathrm{m}^{3}$, and $5.1 \times 10^{14}$ to $2.2 \times 10^{15} \mathrm{spins} /$ $\mathrm{m}^{3}$, respectively (shown in Table $\mathrm{S} 1$ ).

As shown in Figure 2, similar EPR spectra with a single, unstructured signal were obtained for PM with various aerodynamic diameters collected on days with different PM pollution concentrations. The $g$ values and exhibited Lorentzian lines of EPR signals indicated the existence of oxygencontaining semiquinone-type radicals similar to those found in cigarette smoke. ${ }^{38-40} G$ values of 2.003-2.004 indicated the existence of a mixture of oxygen-centered and carbon-centered semiquinone radicals or carbon-centered radicals with an adjacent oxygen atom. ${ }^{3}$ In addition, the $g$ values of all the TSP samples were in the range of 2.00316-2.0034, slightly lower than that of $\mathrm{PM}_{<1 \mu \mathrm{m}}$ samples ranging from 2.003232.00371, which indicated that more oxygen-centered semiquinone radicals were attached to the fine particles. The chemical structures of semiquinone radicals present on the atmospheric PM are shown in Figure S1. The tendency of $g$ values to increase with decreasing particle size was also found in coal samples, which suggested the same adsorption behavior of EPFRs on coal particles and airborne fine particles during the winter heating period. ${ }^{41}$ For smaller particles, more porous structures are bare, and thus provide more available active sites and adsorption sites for EPFRs. Therefore, oxygen in the air was more intense for smaller particles; oxidation may easily occur to produce many more oxygen-centered radicals. It has been demonstrated that the most stabilized resonance structure is as a carbon-centered radical; ${ }^{42}$ moreover, the mode of dimerization for these radicals shows only $\mathrm{C}-\mathrm{C}$ coupling. ${ }^{43}$ In general, both oxygen-centered and carbon-centered radicals exist in atmospheric PM, as oxygen-centered radicals tend to adhere to the smaller particles and carbon-centered radicals mostly on the coarse ones. Therefore, oxygen-centered radicals seem more toxic, along with fine particles, because of their direct effect on the body; carbon-centered radicals on coarse particles should also be highlighted because of their environmental effect, including their stability in air and contributions to the formation of organic pollutants by dimerization. For the line width $(\Delta H p-p)$, there were no coordinate changes (broadening or narrowing) of the EPR signal of all samples; with an average $\Delta H \mathrm{p}$-p ranging from 3.0 to $6.3 \mathrm{G}$, the relatively narrow spectrum indicated the pure component of a family of semiquinone radicals in the sample solutions. ${ }^{44}$

The distribution pattern in Figure 2 showed that EPFR concentrations in each PM fraction increased as the particle size decreased. EPFRs were mostly present in the $\mathrm{PM}_{<1 \mu \mathrm{m}}$ fraction, in which the EPFR concentration was 2-12 times higher than that in $\mathrm{PM}_{1.0-2.5} \mu \mathrm{m}$ and $12-138$ times higher than that in $\mathrm{PM}_{2.5-10 \mu \mathrm{m}}$. Similar quinone characteristics were also found in the PM, which were approximately three times higher in the fine fraction than in the coarse fraction. ${ }^{44}$ Furthermore, it is worth noting that $\mathrm{PM}_{<2.5 \mu \mathrm{m}}$ can travel more deeply into the lungs or even the bloodstream than that of coarse particles, which may induce the generation of harmful reactive oxygen species (ROS) and DNA damage by EPFRs attached to fine particles. ${ }^{45}$ EPR signals of the four-sample series displaying different levels of atmospheric conditions classified according to the mass concentration of $\mathrm{PM}_{<1 \mu \mathrm{m}}$ are shown in Figure 2 and Figure S2. As shown in Figure S2, the concentrations of EPFRs were proportional to the PM pollution levels, which were 
(a)

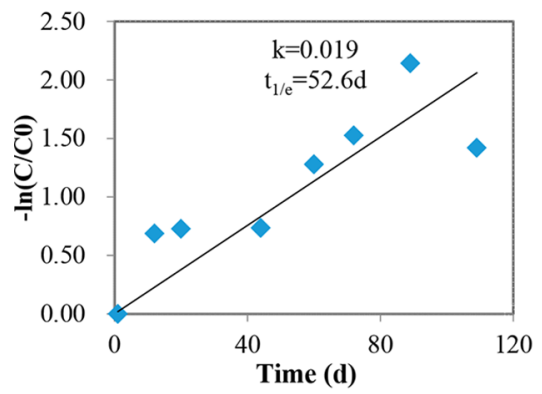

(b)

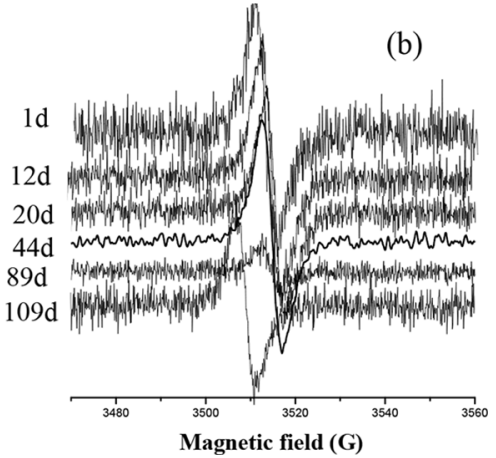

Figure 3. (a) Pseudo-first-order rate law expression fit line of a well-behaved radical signal; (b) evolution of EPR spectra for EPFRs as a function of reaction time.

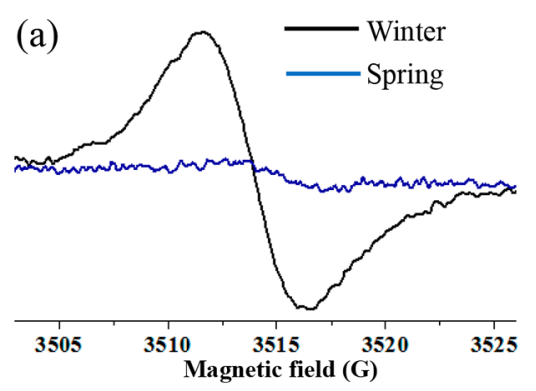

(b)

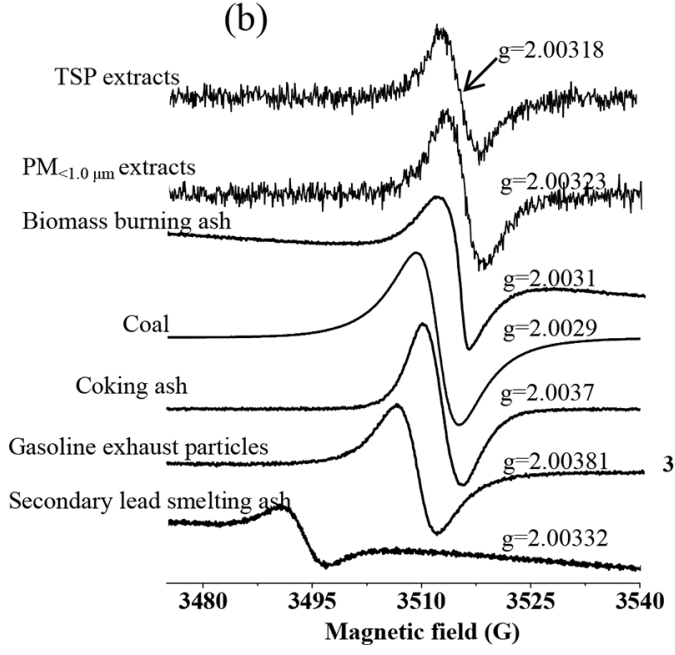

(c)

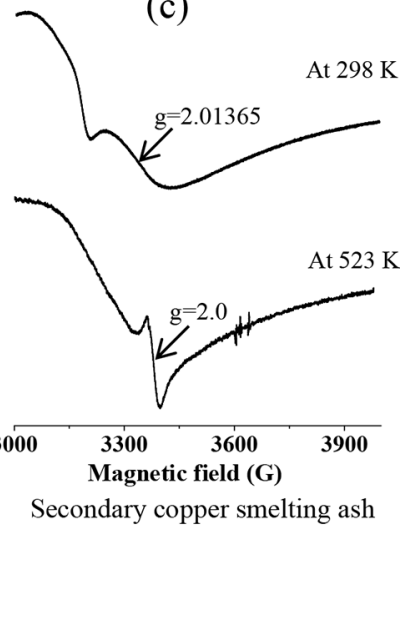

Figure 4. EPR spectra of (a) TSP samples in winter and spring, (b) samples including TSP, $\mathrm{PM}_{<1.0 \mu \mathrm{m}}$, coal, coking ash, biomass burning ash, gasoline exhaust particles, and fly ash of secondary lead smelting ash, and (c) fly ash of secondary copper smelting at 298 and $523 \mathrm{~K}$.

evaluated via the EPFR concentration in TSP and $\mathrm{PM}_{<1.0 \mu \mathrm{m}}$ samples.

Mass concentrations of EPFRs in PM were also calculated in this study, which were in the range of $7.4 \times 10^{19}$ to $3.9 \times 10^{20}$ spins $/ g, 4.7 \times 10^{19}$ to $6.5 \times 10^{20}$ spins $/ g$, ND to $8.2 \times 10^{19}$ spins $/ g$, and $3.1 \times 10^{19}$ to $6.2 \times 10^{20}$ spins $/ g$ in $\mathrm{PM}_{<1 \mu \mathrm{m}}$ $\mathrm{PM}_{1.0-2.5 \mu \mathrm{m}}, \mathrm{PM}_{2.5-10 \mu \mathrm{m}}$, and TSP, respectively. Unit mass concentrations of EPFRs in $\mathrm{PM}_{<1 \mu \mathrm{m}}$ and $\mathrm{PM}_{1.0-2.5 \mu \mathrm{m}}$ fractions were at the same level and were approximately 10 times higher than that of the $\mathrm{PM}_{2.5-10 \mu \mathrm{m}}$ fraction, which were in agreement with Valavanidis et al. ${ }^{44}$ Our results demonstrated that EPFRs were more easily attached to the fine particles, which may be due to the fine particles having a larger surface area and more porous surfaces, resulting in higher adsorption and retention of free radicals. ${ }^{46}$ The mass concentrations of EPFRs in the airborne PM samples were typically $10^{2}-10^{4}$ higher than that in cigarette tar, $10^{2}$ higher than that in the US atmosphere, and 10 times higher than that in the air of industrialized and highly populated locations in the United States. ${ }^{47,48}$ Therefore, as more than $72 \%$ of the total PM mass was contributed by the $\mathrm{PM}_{<2.5 \mu \mathrm{m}}$ fraction and highly elevated levels of EPFRs occurred in fine $\mathrm{PM}$ including $\mathrm{PM}_{<1 \mu \mathrm{m}}$ and $\mathrm{PM}_{1-2.5} \mu \mathrm{m}$, the control of atmospheric pollution, especially for haze events, should attract much more attention for monitoring levels of EPFRs adhered to fine particles $\left(\mathrm{PM}_{<2.5 \mu \mathrm{m}}\right)$.

Evaluation of EPFR Decay. Persistent semiquinone radicals in solid PM may also be persistent in solution, which highlights their toxicological redox properties and lifetime in the liquid environment of lungs or other tissues. Therefore, the 1/e lifetime of EPFRs in the PM extraction solution was evaluated. As a majority amount (52\%-91.1\%) of EPFRs occurred in $\mathrm{PM}_{<1.0 \mu \mathrm{m}}$ a decay study was performed for 

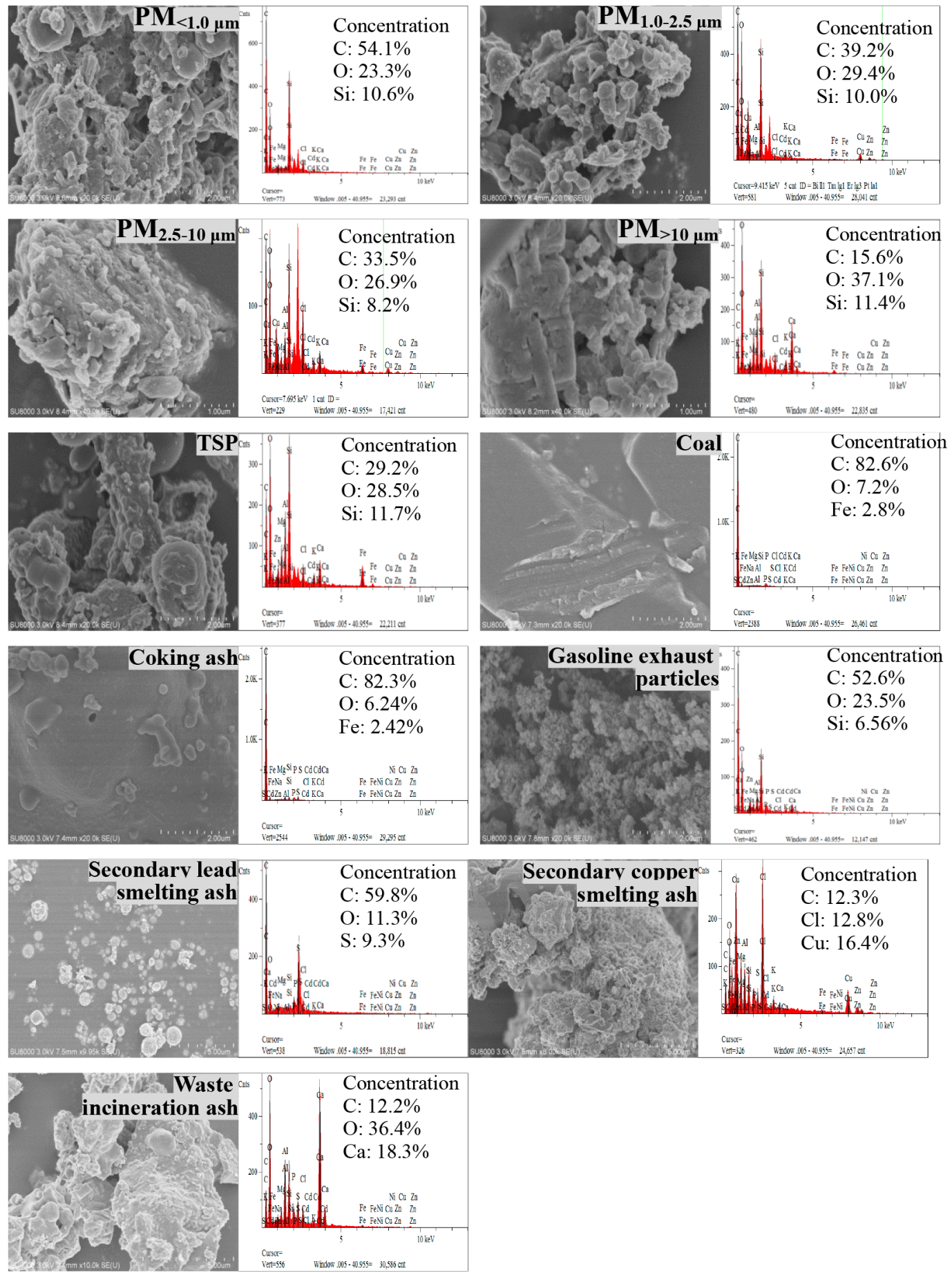

Figure 5. Energy dispersive X-ray spectroscopy (SEM-EDX) of particles from different sources with the top three elemental content of the particles identified.

$\mathrm{PM}_{<1.0 \mu \mathrm{m}}$-associated EPFRs, as shown with the pseudo-firstorder rate law expression fit line of a well-behaved radical signal with diminishing relative intensity in Figure 3a. The slow decay of EPFRs in solutions with an average 1/e lifetime of 59.2 days (range: 24.3-114.9 days) was evaluated, possibly resulting from semiquinone radical decay. Dellinger et al. have proposed that three kinds of EPFR decay occur in solid $\mathrm{PM}_{2.5}$, including the fast decay of the phenoxyl radical with a 1 /e lifetime of $1-21$ days, the slow decay of the semiquinone radical with a $1 / \mathrm{e}$ lifetime of 21-5028 days, and the internal radical with no decay. ${ }^{6}$ EPFR decay in solid samples was different than that of liquid samples in our study; these results question whether only the semiquinone radical in the three types of proposed EPFR decay can persist and be harmful in both a solution and lung environment.

Moreover, there were no coordinate changes (broadening or narrowing) of the EPR signal during the decay process with the $\Delta H$ p-p maintaining an average of $4.70 \pm 0.72 \mathrm{G}$ and the $g$ factor maintaining an average of $2.00329 \pm 0.0001$. $G$ values of all of the samples tended to first decrease and then increase. As oxygen-centered radicals were more active than carboncentered ones, the reduction of oxygen-centered semiquinone 
radicals may have contributed to the declining trend of $g$ values in the first several days. However, even though a slight increase in $g$ values of samples placed in the freezer occurred in the next days, as shown in Figure $3 b$, it was observed in almost all of the samples in the decay experiments, which were sufficient to suggest that the $g$ factor shifted toward more oxygenated radicals through sample oxidation to produce more oxygencentered radicals.

Detection of EPFRs in PM from Potential Sources Contributing to Airborne PM Pollution. EPR signals from automobile exhaust and fly ash collected at different industrial plants were compared with those of airborne PM to explore the possible primary source of EPFRs in atmospheric PM. During the winter, a large amount of coal is combusted to provide warmth in north China, and this season is normally called the heating period. During the heating period, haze events happen frequently. To evaluate the potential contributions of coal burning on the occurrence of EPFRs in airborne PM, an experiment evaluating the EPR signals from TSP samples collected on haze days with a $\mathrm{PM}_{<1.0 \mu \mathrm{m}}$ concentration of approximately $120 \mu \mathrm{g} / \mathrm{m}^{3}$ in the winter (heating period) and spring (nonheating period) was performed. As shown in Figure 4a, EPR signals from TSP samples collected during the winter heating period were much higher than those of spring TSP samples with the same concentration levels of $\mathrm{PM}_{<1.0 \mu \mathrm{m}}$, which indicated the important influence of industrial emissions from coal burning on the elevated levels of EPFRs in atmospheric PM. It has been widely recognized that free radicals can be largely produced and accumulated in coal through trapping in the inner pore surfaces because of pore-diffusional activation energy (see Figure 4b). Despite raw coal containing large quantities of EPFRs, thermal degradation of coal also plays an important role for EPFRs in atmospheric fine particles, during which oxygen-containing radicals and simple aromatic clusters are the most active and important. ${ }^{41}$ During the coal pyrolysis process, the hemolysis of covalent bonds susceptibly occurs to promote the formation of EPFRs, ${ }^{49}$ along with the production of carbon black by collision and polymerization of polycyclic aromatic hydrocarbons.

As shown in Figure 5, elemental carbon accounted for $82.6 \%$ and $82.3 \%$ of all of the elements in the coal and coking ash, respectively. The radicals produced during the coal combustion process adhered to the inner pore surfaces of the carbon black. It was found that even though the particle matter in different samples had similar weights, the deeper was the color of the extraction solution, the higher was the EPFR concentration. SEM-EDX experiments shown in Figure 5 also indicted that EPFRs mainly occurred in particles with higher carbon content. The percentage of carbon content decreased with increasing PM size, which was the same trend observed with EPFR concentrations. Therefore, it was considered that the concentration of EPFRs in the airborne PM was influenced significantly by the amount of carbon black, as a strong correlation between the intensities of EPFRs and elemental carbon $(R=0.87)$ was also found by Tian et al. ${ }^{50}$

Coal combustion, biomass burning, traffic and waste incineration emission, and industrial emissions have been identified as important sources of $\mathrm{PM}_{2.5}{ }^{51}$ Therefore, besides the contribution of coal combustion to EPFRs in the atmosphere during the heating period, other industrial emission and human activities, such as the biomass burning process, copper smelting, lead smelting, and the waste incineration process in the cooling zone, may also be potential EPFR sources owing to the production of large quantities of fly ash containing chlorinated organic compounds and particlesupported metallic oxides, which can easily produce EPFRs on the surface. ${ }^{52,53}$ Dellinger et al. also identified EPFRs associated with PM from almost all combustion sources. ${ }^{48}$ Therefore, EPFRs in the fly ash of several thermal processes, including the biomass burning process, coking process, secondary smelting process, and waste incineration process, were determined as shown in Figure $4 \mathrm{~b}$. Strong signals for organic radicals were detected in the coking ash, gasoline exhaust particles, and biomass burning ash, whose mass concentrations of EPFRs were $1.52 \times 10^{22}$ spins $/ g, 3.0 \times$ $10^{22} \mathrm{spins} / \mathrm{g}$, and $1.14 \times 10^{22} \mathrm{spins} / \mathrm{g}$, respectively, suggesting that mobile exhaust and biomass burning may also play important roles as potential sources of atmospheric EPFRs in addition to the coal combustion process. Moreover, it can be concluded, according to the phenogram shown in Figure 5, that particles with greater pore structure (smaller particle diameter) had a higher EPFR concentration, such as $\mathrm{PM}_{<1.0 \mu \mathrm{m}}$, $\mathrm{PM}_{1.0-2.5 \mu \mathrm{m}}$, gasoline exhaust particles, and biomass burning ash. The results showed that despite the carbon concentration, pore structure also played an important role in EPFR concentration, which further demonstrated that more pore structures can provide more available active sites and adsorption sites for radicals.

Signals of EPFRs in fly ash of a secondary copper smelting process were detected. As shown in Figure 4c, because of the complexity of fly ash in the secondary copper smelting process, signals of multiple organic radicals appeared because of the interference of metals at $298 \mathrm{~K}$ that broadened the width of 179 G. In addition, a dewar was inserted into the cavity of the EPR spectrometer for detection of free radicals during thermochemical reactions. Results showed that evident EPFR signals were observed, with a relative narrower $34 \mathrm{G}$ width. Also, EPFRs in the fly ash of the secondary copper smelting process were also detected and quantified as $1.627 \times 10^{20}$ spins/g, and EPFRs in the fly ash of waste incineration with low carbon content (12.2\%) were not detected. Therefore, despite the contributions to $\mathrm{PM}_{2.5}$ in the air, industrial processes, such as the metal smelting process, also contributed to EPFRs in the atmosphere. However, considering the concentrations of EPFRs varied with changing seasons, which were much higher in coking ash than that of other sources, it can be concluded that coal combustion may be a crucial contributor to EPFR pollution during the winter in Beijing.

In summary, our results indicate that the highest levels of EPFRs, identified as semiquinone radicals, were mainly persistent in the PM fraction of $d_{\mathrm{ae}}<1 \mu \mathrm{m}$. The average $1 / \mathrm{e}$ lifetime of EPFRs in the extraction solutions was estimated to be 59.2 days, which highlighted that EPFRs in PM should be focused on for their potential long-term effects on the environment as well as human health by air inhalation of PM. Occurrence of EPFRs in PM samples collected from human activities, such as coal-burning activities, automobile exhaust, and biomass burning activities, suggested that these events may be potential primary sources of EPFRs in airborne fine particles. Moreover, it can also be speculated that EPFRs may be generated from other types of combustion operations, such as backyard burning and accidental fires, along with the produced PM, as the EPFR formation mechanism is quite similar during these combustion processes. Further studies on EPFR occurrence in various environmental matrices and their effect on human health should be conducted. 


\section{ASSOCIATED CONTENT}

\section{S Supporting Information}

The Supporting Information is available free of charge on the ACS Publications website at DOI: 10.1021/acs.est.7b01929.

Table S1, Figures S1 and S2 (PDF)

\section{AUTHOR INFORMATION}

\section{Corresponding Authors}

*Phone: 010-62949356; e-mail: grliu@rcees.ac.cn.

*Phone: 010-62849172; e-mail: zhengmh@rcees.ac.cn.

\section{ORCID 1}

Guorui Liu: 0000-0002-8462-6734

Rong Jin: 0000-0001-9677-6177

Notes

The authors declare no competing financial interest.

\section{ACKNOWLEDGMENTS}

This work was supported by the National Natural Science Foundation of China (91543108, 21361140359), the Chinese National 973 Program (2015CB453100), the Strategic Priority Research Program of the Chinese Academy of Sciences (XDB14020102), and the Youth Innovation Promotion Association of the Chinese Academy of Sciences (2016038).

\section{REFERENCES}

(1) Mas-Torrent, M.; Crivillers, N.; Rovira, C.; Veciana, J. Attaching Persistent Organic Free Radicals to Surfaces: How and Why. Chem. Rev. 2012, 112, 2506-2527.

(2) Lomnicki, S.; Truong, H.; Vejerano, E.; Dellinger, B. Copper Oxide-Based Model of Persistent Free Radical Formation on Combustion-Derived Particulate Matter. Environ. Sci. Technol. 2008, 42, 4982-4988.

(3) Dellinger, B.; Lomnicki, S.; Khachatryan, L.; Maskos, Z.; Hall, R. W.; Adounkpe, J.; McFerrin, C.; Truong, H. Formation and Stabilization of Persistent Free radicals. Proc. Combust. Inst. 2007, $31,521-528$.

(4) Khachatryan, L.; Vejerano, E.; Lomnicki, S.; Dellinger, B. Environmentally Persistent Free Radicals (EPFRs). 1. Generation of Reactive Oxygen Species in Aqueous Solutions. Environ. Sci. Technol. 2011, 45, 8559-8566.

(5) Gehling, W.; Khachatryan, L.; Dellinger, B. Hydroxyl Radical Generation from Environmentally Persistent Free Radicals (EPFRs) in PM2.5. Environ. Sci. Technol. 2014, 48, 4266-4272.

(6) Gehling, W.; Dellinger, B. Environmentally Persistent Free Radicals and Their Lifetimes in PM2.5. Environ. Sci. Technol. 2013, 47, $8172-8178$

(7) Lubick, N. Persistent Free Radicals: Discovery and Mechanisms for Health Impacts. Environ. Sci. Technol. 2008, 42, 8178-8178.

(8) Mosallanejad, S.; Dlugogorski, B. Z.; Kennedy, E. M.; Stockenhuber, M.; Lomnicki, S. M.; Assaf, N. W.; Altarawneh, M. Formation of $\mathrm{PCDD} / \mathrm{Fs}$ in Oxidation of 2-Chlorophenol on Neat Silica Surface. Environ. Sci. Technol. 2016, 50, 1412-1418.

(9) Altarawneh, M.; Dlugogorski, B. Z. Formation and Chlorination of Carbazole, Phenoxazine, and Phenazine. Environ. Sci. Technol. 2015, 49, 2215-21.

(10) Altarawneh, M.; Dlugogorski, B. Z. Formation of Dibenzofuran, Dibenzo-p-dioxin and Their Hydroxylated Derivatives from Catechol. Phys. Chem. Chem. Phys. 2015, 17, 1822-30.

(11) Altarawneh, M.; Radny, M. W.; Smith, P. V.; Mackie, J. C.; Kennedy, E. M.; Dlugogorski, B. Z.; Soon, A.; Stampfl, C. A Firstprinciples Density Functional Study of Chlorophenol Adsorption on $\mathrm{Cu}_{2} \mathrm{O}$ (110): CuO. J. Chem. Phys. 2009, 130, 184505.

(12) Dela Curz, A. L. N.; Cook, R. L.; Lomnicki, S. M.; Dellinger, B. Effect of Low Temperature Thermal Treatment on Soils Contami- nated with Pentachlorophenol and Environmentally Persistent Free Radicals. Environ. Sci. Technol. 2012, 46, 5971-5978.

(13) Dela Cruz, A. L. N.; Gehling, W.; Lomnicki, S.; Cook, R.; Dellinger, B. Detection of Environmentally Persistent Free Radicals at a Superfund Wood Treating Site. Environ. Sci. Technol. 2011, 45, 6356-6365.

(14) Fang, G. D.; Gao, J.; Liu, C.; Dionysiou, D. D.; Wang, Y.; Zhou, D. M. Key Role of Persistent Free Radicals in Hydrogen Peroxide Activation by Biochar: Implications to Organic Contaminant Degradation. Environ. Sci. Technol. 2014, 48, 1902-1910.

(15) Yang, L. L.; Liu, G. R.; Zheng, M. H.; Zhao, Y. Y.; Jin, R.; Wu, X. L.; Xu, Y. Molecular Mechanism of Dioxin Formation from Chlorophenol based on Electron Paramagnetic Resonance Spectroscopy. Environ. Sci. Technol. 2017, 51, 4999-5007.

(16) Jia, H. Z.; Nulaji, G.; Gao, H. W.; Wang, F.; Zhu, Y. Q.; Wang, C. Y. Formation and Stabilization of Environmentally Persistent Free Radicals Induced by the Interaction of Anthracene with $\mathrm{Fe}(\mathrm{III})$ Modified Clays. Environ. Sci. Technol. 2016, 50, 6310-6319.

(17) Dugas, T. R.; Lomnicki, S.; Cormier, S. A.; Dellinger, B.; Reams, M. Addressing Emerging Risks: Scientific and Regulatory Challenges Associated with Environmentally Persistent Free Radicals. Int. J. Environ. Res. Public Health 2016, 13, 573.

(18) Wu, S.; Ni, Y.; Li, H.; Pan, L.; Yang, D.; Baccarelli, A. A.; Deng, F.; Chen, Y.; Shima, M.; Guo, X. Short-term Exposure to High Ambient Air Pollution Increases Airway Inflammation and Respiratory Symptoms in Chronic Obstructive Pulmonary Disease Patients in Beijing, China. Environ. Int. 2016, 94, 76-82.

(19) Chi, G. C.; Hajat, A.; Bird, C. E.; Cullen, M. R.; Griffin, B. A.; Miller, K. A.; Shih, R. A.; Stefanick, M. L.; Vedal, S.; Whitsel, E. A.; Kaufman, J. D. Individual and Neighborhood Socioeconomic Status and the Association between Air Pollution and Cardiovascular Disease. Environ. Health Persp. 2016, 124, 1840-1847.

(20) Assaf, N. W.; Altarawneh, M.; Oluwoye, I.; Radny, M.; Lomnicki, S. M.; Dlugogorski, B. Z. Formation of Environmentally Persistent Free Radicals on $\alpha$-Al2O3. Environ. Sci. Technol. 2016, 50, 11094-11102.

(21) Vejerano, E.; Lomnicki, S.; Dellinger, B. Formation and Stabilization of Combustion-Generated Environmentally Persistent Free Radicals on an $\mathrm{Fe}(\mathrm{III})(2) \mathrm{O}-3 /$ Silica Surface. Environ. Sci. Technol. 2011, 45, 589-594.

(22) Sun, Y.; Chen, C.; Zhang, Y.; Xu, W.; Zhou, L.; Cheng, X.; Zheng, H.; Ji, D.; Li, J.; Tang, X.; Fu, P.; Wang, Z. Rapid Formation and Evolution of an Extreme Haze Episode in Northern China during winter 2015. Sci. Rep. 2016, 6, 27151.

(23) Huang, R. J.; Zhang, Y.; Bozzetti, C.; Ho, K. F.; Cao, J. J.; Han, Y.; Daellenbach, K. R.; Slowik, J. G.; Platt, S. M.; Canonaco, F.; Zotter, P.; Wolf, R.; Pieber, S. M.; Bruns, E. A.; Crippa, M.; Ciarelli, G.; Piazzalunga, A.; Schwikowski, M.; Abbaszade, G.; Schnelle-Kreis, J.; Zimmermann, R.; An, Z.; Szidat, S.; Baltensperger, U.; El Haddad, I.; Prevot, A. S. High Secondary Aerosol Contribution to Particulate Pollution during Haze Events in China. Nature 2014, 514, 218-222.

(24) Sun, Y. L.; Chen, C.; Zhang, Y. J.; Xu, W. Q.; Zhou, L. B.; Cheng, X. L.; Zheng, H. T.; Ji, D.; Li, J. S.; Tang, X.; Fu, P. Q.; Wang, Z. F. Rapid Formation and Evolution of an Extreme Haze Episode in Northern China during winter 2015. Sci. Rep. 2016, 6, 27151.

(25) Hoek, G.; Raaschou-Nielsen, O. Impact of Fine Particles in Ambient Air on Lung Cancer. Aizheng 2014, 33, 197-203.

(26) McGinnis, J. E.; Heo, J. B.; Olson, M. R.; Rutter, A. P.; Schauer, J. J. Understanding the Sources and Composition of the Incremental Excess of Fine Particles Across Multiple Sampling Locations in One Air Shed. J. Environ. Sci. 2014, 26, 818-826.

(27) Tillett, T. Hearts over Time Cardiovascular Mortality Risk Linked to Long-Term PM2.5 Exposure. Environ. Health Perspect. 2012, 120, A205-A205.

(28) Valavanidis, A.; Fiotakis, K.; Vlachogianni, T. Airborne Particulate Matter and Human Health: Toxicological Assessment and Importance of Size and Composition of Particles for Oxidative Damage and Carcinogenic Mechanisms. J. Environ. Sci. Health, Part C 2008, 26, 339-362. 
(29) Franck, U.; Herbarth, O.; Roder, S.; Schlink, U.; Borte, M.; Diez, U.; Kramer, U.; Lehmann, I. Respiratory Effects of Indoor Particles in Young Children are Size Dependent. Sci. Total Environ. 2011, 409, $1621-1631$.

(30) Zhu, Q.; Zhang, X.; Dong, S.; Gao, L.; Liu, G.; Zheng, M. Gas and Particle Size Distributions of Polychlorinated Naphthalenes in the Atmosphere of Beijing, China. Environ. Pollut. 2016, 212, 128-134.

(31) Zhang, X.; Zheng, M.; Liang, Y.; Liu, G.; Zhu, Q.; Gao, L.; Liu, W.; Xiao, K.; Sun, X. Particle Size Distributions and Gas-particle Partitioning of Polychlorinated Dibenzo-p-dioxins and Dibenzofurans in Ambient Air during Haze Days and Normal Days. Sci. Total Environ. 2016, 573, 876-882.

(32) Lelieveld, J. Atmospheric Chemistry: A Missing Sink for Radicals. Nature 2010, 466, 925-926.

(33) Jakober, C. A.; Riddle, S. G.; Robert, M. A.; Destaillats, H.; Charles, M. J.; Green, P. G.; Kleeman, M. J. Quinone Emissions from Gasoline and Diesel Motor Vehicles. Environ. Sci. Technol. 2007, 41, $4548-4554$

(34) Vejerano, E.; Lomnicki, S. M.; Dellinger, B. Formation and Stabilization of Combustion-generated, Environmentally Persistent Radicals on $\mathrm{Ni}(\mathrm{II}) \mathrm{O}$ Supported on a Silica Surface. Environ. Sci. Technol. 2012, 46, 9406-9411.

(35) Nwosu, U. G.; Khachatryan, L.; Youm, S. G.; Roy, A.; dela Cruz, A. L. N.; Nesterov, E. E.; Dellinger, B.; Cook, R. L. Model System Study of Environmentally Persistent Free Radicals Formation in a Semiconducting Polymer Modified Copper Clay System at Ambient Temperature. RSC Adv. 2016, 6, 43453-43462.

(36) Kiruri, L. W.; Khachatryan, L.; Dellinger, B.; Lomnicki, S. Effect of Copper Oxide Concentration on the Formation and Persistency of Environmentally Persistent Free Radicals (EPFRs) in Particulates. Environ. Sci. Technol. 2014, 48, 2212-2217.

(37) Jia, H. Z.; Zhao, S.; Nulaji, G.; Tao, K. L.; Wang, F.; Sharma, V. K.; Wang, C. Environmentally Persistent Free Radicals in Soils of Past Coking Sites: Distribution and Stabilization. Environ. Sci. Technol. 2017, 51, 6000 .

(38) Liu, J.; Jiang, X.; Han, X.; Shen, J.; Zhang, H. Chemical Properties of Superfine Pulverized Coals. Part 2. Demineralization Effects on Free Radical Characteristics. Fuel 2014, 115, 685-696.

(39) Lingard, J. J. N.; Tomlin, A. S.; Clarke, A. G.; Healey, K.; Hay, A. W. M.; Wild, C. P.; Routledge, M. N. A Study of Trace Metal Concentration of Urban Airborne Particulate Matter and its Role in Free Radical Activity as Measured by Plasmid Strand Break Assay. Atmos. Environ. 2005, 39, 2377-2384.

(40) Pryor, W. A.; Stone, K.; Zang, L. Y.; Bermudez, E. Fractionation of Aqueous Cigarette Tar Extracts: Fractions that Contain the Tar Radical Cause DNA Damage. Chem. Res. Toxicol. 1998, 11, 441-448. (41) Liu, J.; Jiang, X.; Shen, J.; Zhang, H. Influences of Particle Size, Ultraviolet Irradiation and Pyrolysis Temperature on Stable Free Radicals in Coal. Powder Technol. 2015, 272, 64-74.

(42) Font-Sanchis, E.; Aliaga, C.; Focsaneanu, K. S.; Scaiano, J. C. Greatly Attenuated Reactivity of Nitrile-Derived Carbon-Centered Radicals Toward Oxygen. Chem. Commun. 2002, 1576-1577.

(43) Neumann, W. P.; Stapel, R. Über sterisch gehinderte freie Radikale, XVI. Zur Existenz von Tetraphenylbernsteinsäure und ihrer Ester sowie über die Struktur der Dimeren der Diarylmethyl-Radikale $\mathrm{Ar}_{2} \mathrm{C}-\mathrm{X}, \mathrm{X}=\mathrm{CO}_{2} \mathrm{R}, \mathrm{CN}, \mathrm{COR}$ Chem. Ber. 1986, 119, 3422-3431.

(44) Valavanidis, A.; Fiotakis, K.; Vlahogianni, T.; Papadimitriou, V.; Pantikaki, V. Determination of Selective Quinones and Quinoid Radicals in Airborne Particulate Matter and Vehicular Exhaust Particles. Environ. Chem. 2006, 3, 233.

(45) Dellinger, D.; Pryor, A.; Cueto, C.; Squadrito, L. S.; Hegde, V.; Deutsch, W. A. Role of Free Radicals in the Toxicity of Airborne Fine Particulate Matter. Chem. Res. Toxicol. 2001, 14, 1371-1377.

(46) Liu, C.; Shi, S.; Weschler, C.; Zhao, B.; Zhang, Y. Analysis of the Dynamic Interaction Between SVOCs and Airborne Particles. Aerosol Sci. Technol. 2013, 47, 125-136.

(47) Pryor, W. A.; Prier, D. G.; Church, D. F. Electron-spin Resonance Study of Mainstream and Sidestream Cigarette Smoke:
Nature of the Free Radicals in Gas-Phase Smoke and in Cigarette Tar. Environ. Health Persp. 1983, 47, 345-355.

(48) Saravia, J.; Lee, G. I.; Lomnicki, S.; Dellinger, B.; Cormier, S. A. Particulate Matter Containing Environmentally Persistent Free Radicals and Adverse Infant Respiratory Health Effects: A Review. J. Biochem. Mol. Toxicol. 2013, 27, 56-68.

(49) Green, U.; Aizenshtat, Z.; Ruthstein, S.; Cohen, H. Stable Radicals Formation in Coals Undergoing Weathering: Effect of Coal Rank. Phys. Chem. Chem. Phys. 2012, 14, 13046-13052.

(50) Tian, L.; Koshland, C. P.; Yano, J.; Yachandra, V. K.; Yu, I. T.; Lee, S. C.; Lucas, D. Carbon-Centered Free Radicals in Particulate Matter Emissions from Wood and Coal Combustion. Energy Fuels 2009, 23, 2523-2526.

(51) Zhang, R.; Jing, J.; Tao, J.; Hsu, S. C.; Wang, G.; Cao, J.; Lee, C. S. L.; Zhu, L.; Chen, Z.; Zhao, Y.; Shen, Z. Chemical Characterization and Source Apportionment of $\mathrm{PM}<\mathrm{sub}>2.5</$ sub $>$ in Beijing: Seasonal Perspective. Atmos. Chem. Phys. 2013, 13, 7053-7074.

(52) Altwicker, E. R.; Konduri, R. K. N. V.; Lin, C.; Milligan, M. S. Rapid Formation of Polychlorinated Dioxins Furans in the Post Combustion Region during Heterogeneous Combustion. Chemosphere 1992, 25, 1935-1944.

(53) Tuan, Y.-J. Formation of PCDD/Fs in the Cooling Down Process of Incineration Flue Gas. Aerosol Air Qual. Res. 2012, 12, $1309-1314$ 